\title{
Epilepsy in a mitochondrial disorder
}

\author{
Torberg Torbergsen, Ellisiv Mathiesen, Jan Aasly
}

\begin{abstract}
In a large family with maternally inherited mitochondrial disease, a mild defect in the NADH-ubiquinone oxidoreductase step (complex 1) in the respiratory chain was found. Epilepsy was seen in nine $(22 \%)$ of the 37 family members. Five of them, belonging to one branch of the family, had myoclonus epilepsy and EEG abnormalities consistent with this. The remaining four patients, belonging to other branches of the family tree, had partial epilepsy. Neurological symptoms also varied in different parts of the family. Possible explanations for the differences in phenotypic expressions are discussed.
\end{abstract}

The mitochondrial disorders represent a group of diseases in which defects in the oxidative metabolism are found. This inborn defect is localised to mitochondria and is most often considered to be systemic. Organs with a high demand for energy via this metabolic pathway are most vulnerable. Symptoms therefore arise from brain, auditory pathways, and peripheral nerves as well as skeletal and heart muscles. The mitochondrial DNA codes for 13 sub-units of the enzymes of the respiratory chain which comprise about $10 \%$ of the mitochondrial proteins. The remainder is coded by nuclear DNA. Mendelian as well as mitochondrial inheritance is therefore seen in these disorders. ${ }^{1}$ Most reported cases, however, have been sporadic. ${ }^{2}$

In recent years several defects in oxidative metabolism have been identified as causes of various mitochondrial diseases. There is rapidly increasing knowledge concerning this group of disorders. ${ }^{3}$

The metabolic defect produces cellular dysfunction and structural changes gradually

and in final revised form 13 February 1991.

Accepted 28 February 1991 follow. Atrophic changes are seen in the central and peripheral nervous system and in skeletal muscles. Functional disturbances as well as organic changes in cerebral tissue are known to cause epilepsy. It is conceivable therefore that epilepsy with different clinical manifestations could occur as a result of functional or organic lesions in these patients. The occurrence of epilepsy in these disorders has been known for several years. Special attention has been paid to myoclonus epilepsy. ${ }^{45}$ A clinical entity, myoclonus epilepsy with ragged red fibres (MERRF) has been pointed out. ${ }^{35}$ In the large family with mitochondrial myopathy and myoclonus epilepsy reported by Rosing et al, ${ }^{6}$ mitochondrial inheritance was assumed.

Generalised and focal seizures in patients with mitochondrial myopathy are also reported, and are seen in patients with the clinical picture of mitochondrial encephalomyopathy, lactic acidosis and strokelike episodes (MELAS). ${ }^{7}$ Mutations of muscle mitochondrial DNA have recently been identified in patients with $M E R R F^{8}$ and MELAS. ${ }^{9}$

We describe patients with myoclonus epilepsy and patients with partial epilepsy belonging to different branches of a large family with mitochondrial encephalomyopathy with maternal inheritance.

\section{Material and methods}

We studied a four generation family with mitochondrial encephalomyopathy (fig 1). All members in generations I and II were dead. The age of the patients in generation III ranged from 42-67 years. In generation IV the age distribution was 18-35 years. Neurological examinations were performed on 22 members. Information about the other family members was obtained from medical records and/or from relatives.

Muscle biopsy and lumbar puncture were performed on 12 patients $(12,14,16,17,18$, $19,20,21,24,27,31,35$ ) and lumbar puncture on patient 10. Light and electron microscopic studies were carried out on all the biopsies. In the biopsy from patient 20, respiratory studies of the mitochondria were performed. Purified mitochondrial preparations were used immediately for polarographic determination of oxygen uptake and for lowtemperature spectral study of cytochromes according to techniques described by Morgan-Hughes et al..$^{10}$ The levels of lactate and pyruvate were estimated in spinal fluid and in blood. EEG was performed in 21 patients and $20(10,12,14,16-24,27,31$, 35-39) had had cerebral CT. 


\section{Results}

General clinical features

Among the offspring of patient 7 (see pedigree in fig 1) clinical symptoms were very homogeneous although severity varied. In siblings 16-24 hearing loss, ataxia, pigmental retinal degeneration as well as muscular fatigue and weakness were found. Electrophysiological studies revealed myopathy, and in those most affected, polyneuropathy as well (described in more detail in reference 11). Patients 34-39 were only slightly affected. Except for hearing loss in four of them, there were no subjective symptoms of disease. As in several other women in this family two of them (34 and 36) had developed eclampsia. ${ }^{12}$

Among the patients in other branches of the family, the clinical manifestations were more variable. Some were severely affected $(3,12$, $15)$, others less so (14, aged 67) and some only subclinically (31, aged 35). Predominant symptoms and signs varied considerably between patients in this group. Pronounced muscular weakness $(15,28)$, hearing loss $(10,14)$, partial epilepsy and psychiatric symptoms were found $(3,10)$. Three patients $(13,21,28)$ died of severe infectious diseases.

\section{Laboratory findings}

The EEG was abnormal in the eight patients with a history of epilepsy in which it was performed (table). In the 12 other patients studied, the EEG was abnormal in 10, mostly because of an increased amount of unspecific theta-activity. In the non-epileptic patient (34) the EEG showed bursts of spike waves, and two of her sisters $(36,37)$ had episodic rhythmic theta-activity.

The CT scan was abnormal in all 20 patients in whom it was obtained. Cortical and cerebellar atrophy were the most prominent findings. In four patients $(16,20,24,31)$ calcifications of the basal ganglia were found. In some younger members of the family, CT abnormalities were mild.

In the proband (20), muscle biopsy stained with Gomori trichrome showed 5\% ragged-red fibres. This increased to $12-15 \%$ with succinate dehydrogenase reaction. Electron microscopic study revealed subsarcolemmal accumulations of abnormal mitochondria and crystalline inclusion bodies.

Muscles biopsies stained with Gomori trichrome from the other 11 patients showed ragged-red fibres in only one. However, in $\mathrm{NADH}$ staining, five other biopsies contained fibres with subsarcolemmal amorphous material. Electronmicroscopic studies revealed subsarcolemmal clusters of mitochondria abnormal in size and shape in all, and crystalline inclusion bodies were found in six patients. The resting value of lactate and pyruvate in the blood was normal. In the spinal fluid, the lactate level was raised in four out of six patients with epilepsy (range 1526-8986 $\mu \mathrm{M} / \mathrm{L}$, mean value 3963 ) compared to range 1634-2270 in normal subjects.

In the seven non-epileptic patients the lactate level in the spinal fluid was raised in all (range 3040-4229 uM/L, mean value 3738).

The respiratory study of the muscle biopsy from the proband revealed a mild defect in the NADH-ubiquinone oxidoreductase step, while the spectral study of isolated mitochondria showed a low cytochrome aa 3 content [0,18 nmoles/mg, 0,43(0,05)].

\section{Case reports of patients with epilepsy}

Case 3 Born in 1883, this patient had had epileptic seizures from the age of 22 . According to medical records he had partial complex as well as tonic-clonic fits. During the following years his cognitive functions gradually declined, and his epilepsy disorder became more severe. From 1931-45 he became institutionalised in a hospital for epileptics. In 1939 his IQ was estimated to be 45 . EEG and CT were not available at that time. The patient died at the age of 67, probably as a result of suicide.

Case 10 This 47 years old woman had had epileptic seizures from the age of six months. At four years of age she developed a right sided moderate hemiparesis which has persisted. Her seizures were focal with initial epigastric rising sensations, followed by jerks in the right hand and adverse turning of the head. Sometimes the seizures became generalised, with loss of con-

Table Clinical features and EEG and CT findings in nine patients with epilepsy

\begin{tabular}{|c|c|c|c|c|c|}
\hline Patient & Sex/age & Clinical features & Epilepsy manifestation & $E E G$ & $C T$ \\
\hline $\begin{array}{l}\text { Case } 3 \\
\text { Case } 10\end{array}$ & $\begin{array}{l}M / 57 \\
F / 47\end{array}$ & $\begin{array}{l}\text { Severe intellectual deterioration } \\
\text { At age } 4 \text { right sided hemiplegia } \\
\text { Paranoid psychosis } \\
\text { Hearing loss }\end{array}$ & $\begin{array}{l}\text { CPS with secondary generalisation } \\
\text { CPS and simple partial seizures }\end{array}$ & $\begin{array}{l}\text { Focal slowing and spikes } \\
\text { left parietal region }\end{array}$ & $\begin{array}{l}\text { Moderate cerebellar } \\
\text { atrophy }\end{array}$ \\
\hline Case 12 & $\mathrm{~F} / 50$ & $\begin{array}{l}\text { Intellectual deterioration from } \\
\text { early adolescence }\end{array}$ & CPS, sometimes generalised & $\begin{array}{l}\text { Moderate slowing } \\
\text { Sometimes sharp waves } \\
\text { left temporal region }\end{array}$ & $\begin{array}{l}\text { Pronounced cerebellar } \\
\text { atrophy, mild cortical } \\
\text { cerebral atrophy }\end{array}$ \\
\hline Case 18 & $M / 58$ & $\begin{array}{l}\text { Mild muscular weakness } \\
\text { Pigmental retinal deg } \\
\text { Progressive hearing loss } \\
\text { Mild cerebellar ataxia }\end{array}$ & Myclonic epilepsy & $\begin{array}{l}\text { Episodic bilateral slow } \\
\text { waves }\end{array}$ & $\begin{array}{l}\text { Cerebellar and cortical } \\
\text { cerebral atrophy }\end{array}$ \\
\hline Case 20 & $\mathbf{F} / 52$ & As in case 18 & Myoclonic epilepsy & $\begin{array}{l}\text { Bursts bilateral irregular } \\
\text { spikes waves }\end{array}$ & $\begin{array}{l}\text { Cortical cerebral and } \\
\text { cerebellar atrophy } \\
\text { Calcination basal ganglia }\end{array}$ \\
\hline Case 22 & $M / 48$ & As in case 18 & $\begin{array}{l}\text { Myoclonic jerks on } \\
\text { photic stimulation }\end{array}$ & $\begin{array}{l}\text { Rhythmic theta activity } \\
\text { and occipital spikes during } \\
\text { photic stimulation }\end{array}$ & $\begin{array}{l}\text { Moderate cortical cerebral } \\
\text { and cerebellar atrophy }\end{array}$ \\
\hline $\begin{array}{l}\text { Case } 23 \\
\text { Case 24 } \\
\text { Case } 27\end{array}$ & $\begin{array}{l}M / 46 \\
M / 42 \\
M / 17\end{array}$ & $\begin{array}{l}\text { As in case } 18 \\
\text { As in case } 18 \\
\text { Mild intellectual deterioration }\end{array}$ & $\begin{array}{l}\text { As in case } 22 \\
\text { As in case } 22 \\
\text { Simple partial seizures } \\
\text { with generalisation }\end{array}$ & $\begin{array}{l}\text { As in case } 22 \\
\text { As in case } 22 \\
\text { Generalised slowing } \\
\text { Spikes right fronto-temporal } \\
\text { region }\end{array}$ & $\begin{array}{l}\text { As in case } 22 \\
\text { As in case } 20 \\
\text { Moderate cerebellar } \\
\text { atrophy }\end{array}$ \\
\hline
\end{tabular}




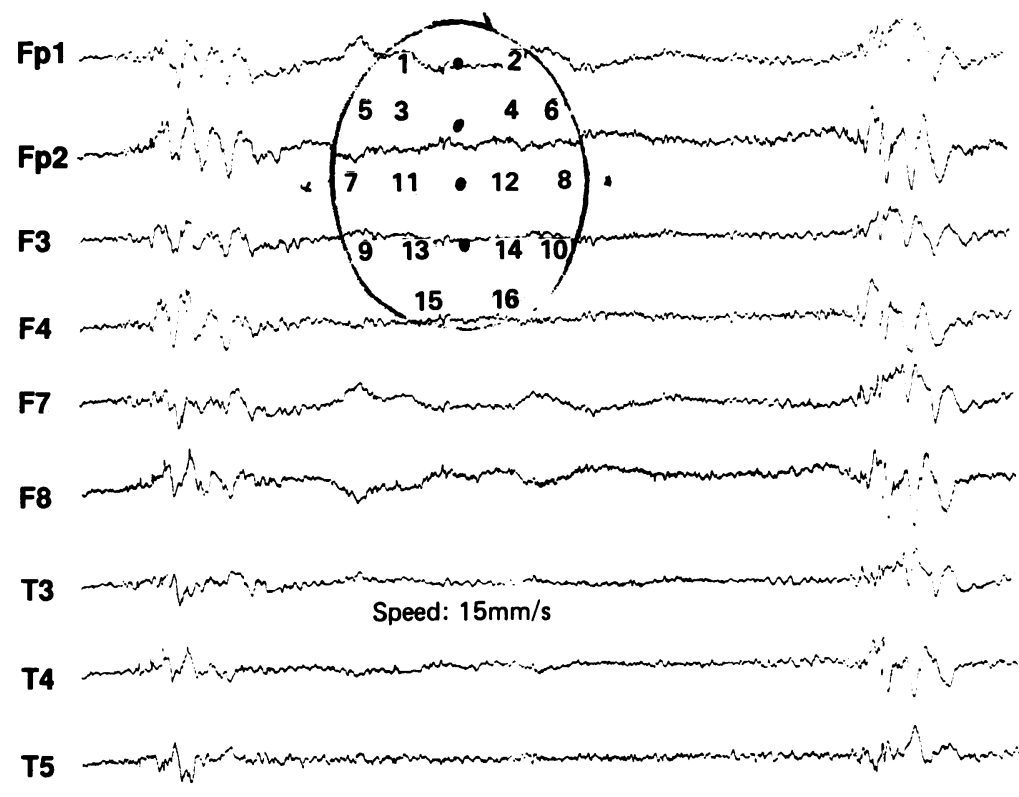

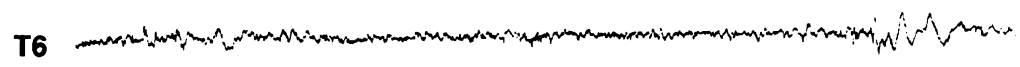
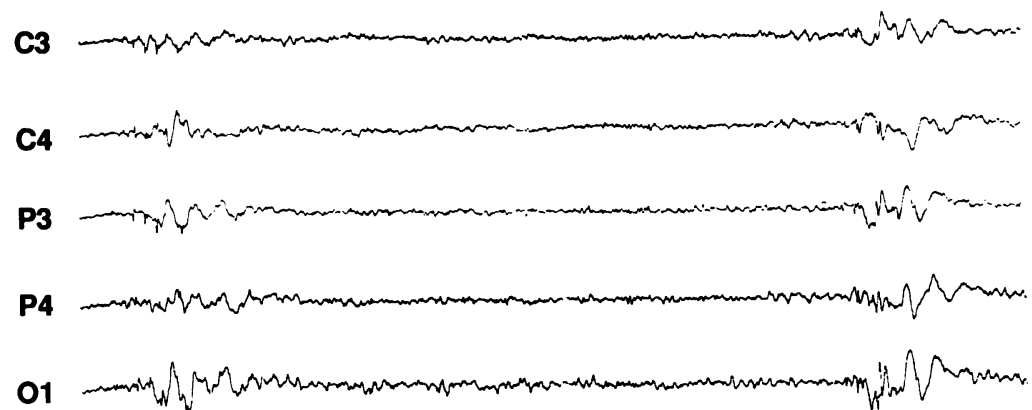

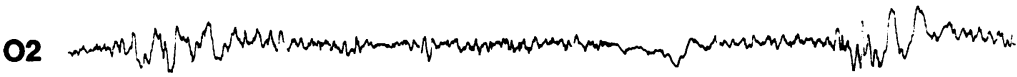
$\int_{1 \mathrm{~s}} 100 \mu \mathrm{V}$

Figure 2 Monopolar EEG recording with average reference in patient 20 showing bursts of bilateral irregular spike waves.

sciousness lasting up to one minute. Her severe epilepsy had necessitated numerous admissions to specialist hospitals. She had had pronounced psychiatric symptoms including psychotic and paranoid reactions. At the age of 10 her IQ was normal but subsequent examinations indicated gradual mental retardation. Basal metabolic rate was $75-80 \%$ at the age of 25 despite normal thyroid function. At the age of 47 there was a fairly pronounced sensorineural hearing loss. Cerebral CT revealed moderate cerebellar atrophy. Several EEGs were all abnormal, with generalised slow activity, and frequently exhibiting focal slowing in the left parietal region. Focal spike activity was also noted.

Case 12 The patient was a 50 year old woman who had had epilepsy since the age of 12 . They were usually complex partial seizures (CPS); rarely generalised tonic-clonic fits. Between the age of 12-13 years she deteriorated mentally. Since the age of $18-19$ years she has had pronounced ataxia. CT showed severe cerebellar and moderate cortical atrophy. Moderate polyneuropathy was found on electrophysiological testing. The lactate level in the spinal fluid was elevated ( $3950 \mathrm{uM} / \mathrm{L})$. Electron microscopy of skeletal muscle revealed only very slight subsarcolemmal accumulation of mitochondria. EEG showed moderate slowing, most conspicuous in the left temporal region where sharp waves were seen.

Cases 18, 20, 22, 23, 23 These siblings, aged between 42-58 years, had similar medical histories and clinical findings, and are reported together. All had progressive hearing loss over several years. Four of them used hearing aids. Cerebellar ataxia, retinal pigmental degeneration and varying degrees of muscular weakness and fatigue were found in all of them. Patients 18 and 20 had mild spontaneous myoclonus. In patient 22, 23 and 24 myoclonic jerks were seen on photic stimulation. Increased levels of spinal fluid lactate and characteristic morphological mitochondria with electron microscopy, were found in the four patients in whom these investigations were performed. In patient number 20 the EEG showed bursts of bilateral atypical spike waves (fig 2). In patients 22,23 and 24 rhythmic theta activity and occipital spikes were seen during photic stimulation which also provoked myoclonic jerks.

Case 27 A 17 year old man, son of case 2 had experienced partial motor and generalised epileptic seizures since the age of 12 . Neurological examination, EMG, blood and CSF lactate levels and routine blood tests were normal. Electron microscopic studies showed very slight subsarcolemmal clustering of mitochondria with some increased variation in size. CT revealed atrophy of the cerebellar vermis and slight widening of the cerebral sulci. EEG showed generalised slowing and spikes localised to the right fronto-temporal region (fig 3).

\section{Discussion}

In this family there are different clinical expressions of epilepsy: myoclonus, partial epilepsy and generalised tonic-clonic fits were present. These are known to occur in mitochondrial disorders, and can be seen in the same patient. Unique to this family are the various clinical expressions of epilepsy and other neurological symptoms. While a homogeneous clinical picture was present in one branch, great diversity was seen in the rest of the family.

Among the offspring of patient 7 myoclonus represented the only type of epileptic seizures and was present in five out of these 17 family members. The myoclonus was mild, and none of the patients had sought medical attention because of it. In one patient with myoclonus (20), as well as in her non-epileptic daughter (34), bilateral irregular spike waves were seen in the EEG, while a bilateral paroxysmal response to photic stimulation was the only abnormality present in three other patients. Abnormalities included rhythmic thetaactivity and occipital spikes. Photoparoxysmal abnormalities are related to hyperexcitability in cerebral neurons. This has been reported in 


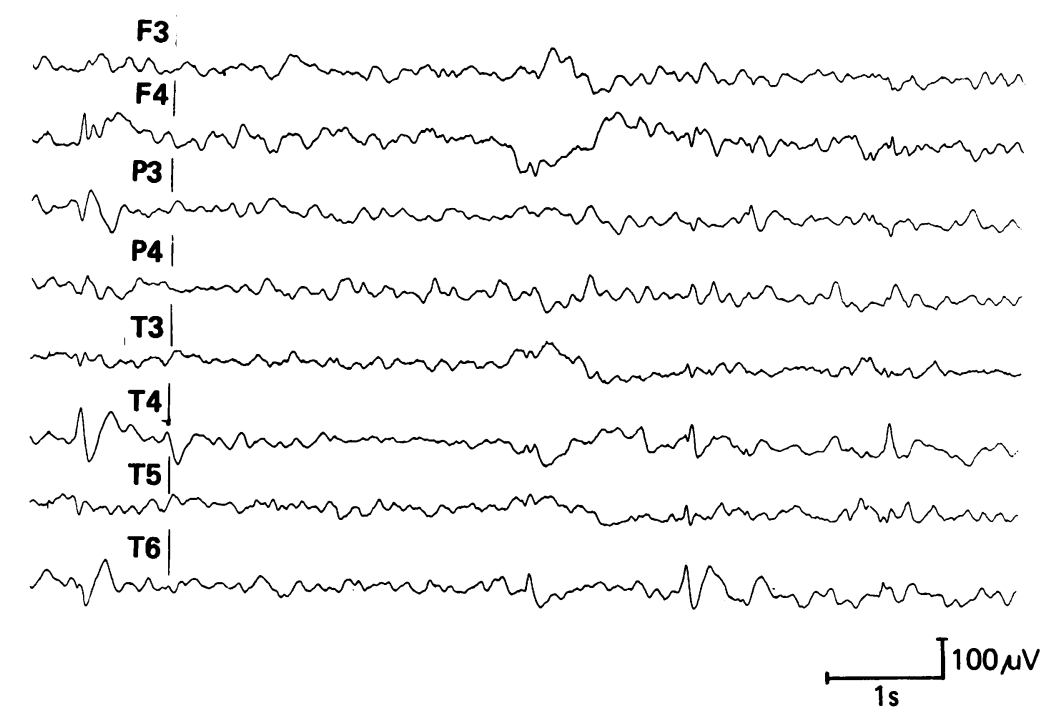

Figure 3 Monopolar EEG recording with average reference in patient 27 showing generally slowing and focal spikes in the right frontotemporal region.

other studies of patients with this type of metabolic disease. ${ }^{6}$

Myoclonus epilepsy is seen in various syndromes. In some of these a metabolic defect is well defined; $;^{513}$ in other syndromes, however, the aetiology is still unknown. It is reasonable to suspect that mitochondrial dysfunctions may be the cause of some of the undefined syndromes-in which myoclonus is present. In two of our younger patients without myoclonic symptoms (36 and 37 , both in their early twenties), episodic rhythmic theta activity was found. It is interesting that bursts of spike and waves were seen in their sister, who did not have clinical myoclonus. Doose et $a l^{14}$ in a genetic study, have claimed that this type of theta rhythm is a sign of functional abnormality, correlated with an increased susceptibility to seizure. They also suggested that spikes and waves become manifest only if the basic functional anomaly which is responsible for the occurrence of theta rhythms exceeds a certain degree.

The epilepsy among patients in the other branches of the family is partial motor and/or complex partial epilepsy; a type which is assumed to be caused by organic brain lesions. Atrophic changes were found in all patients in this family in whom CT had been performed. In some patients the changes were mild. Except for the occurrence of hemiparesis at the age of four in patient 10 (symptoms consistent with MELAS), none of the patients had symptoms of focal cerebral lesions other than epilepsy.

The various clinical manifestations of epilepsy in different branches of our family are remarkable. Assuming that the mutation defect in mitochondrial DNA is identical in our patients, other factors should influence the clinical expression. It has been claimed that the severity and type of clinical symptoms are dependent upon the random distribution of wildtype and mutant mitochondria in cell division. ${ }^{15} \mathrm{~A}$ more homoplasmic population of mitochondria in the ova from patient 7 compared with the ova from the mothers of the other family branches is probable, but this is not the only explanation for the unique distribution of symptoms. In one branch of the family all nine siblings (16-24) have essentially identical clinical pictures, including the type of epileptic symptoms while in other branches neurological symptoms are much more variable. Nuclear DNA codes enzymes involved in the transcription and transmission of mitochondrial DNA and have an effect upon mitochondrial gene expression. ${ }^{16}$ Furthermore, a mutation in the mitochondrial genome will alter the expression of nuclear genes. ${ }^{17}$ An intergenomic regulation may influence the clinical expression of mitochondrial mutations. It is therefore possible that the genotype of the fathers may have an effect on the phenotypic expression in this maternally inherited disorder.

The four patients with partial epilepsy were treated in different neurological departments, but the aetiological diagnosis was made "occasionally" in connection with examination of other family members. This group of disorders may be underdiagnosed in both neurological and psychiatric patients. Reports concerning successful therapeutic trials of patients with defects localised to the oxidative metabolism in the mitochondria have been published, ${ }^{18}$ and it seems reasonable to expect further progress in this field. A correct aetiological diagnosis in these patients will therefore be of increasing importance.

We thank Dr John A Morgan-Hughes, London, for performing the biochemical analysis of muscle biopsy and Dr Sigurd Lindal for performing the electron microscopic studies.

1 Wallace DC. Mitochondrial DNA mutations and neuromuscular disease. Hum Gen Dis 1989;5(1):9-13.

2 Harding AE, Petty RK, Morgan-Hughes JA. Mitochondrial myopathy: a genetic study of 71 cases. J Med Gen 1988; 25:528-35.

3 DiMauro S, Bonilla E, Zeviani M, Nakagawa M, DeVivo DC. Mitochondrial myopathies. Ann Neurol 1985;17: 521-38.

4 Lombes A, Mendell JR, Nakase H, et al. Myoclonic epilepsy and ragged-red fibers with cytochrome oxidase deficiency: neuropathology, biochemistry, and molecular genetics. Ann Neurol 1989;26:20-33.

5 Berkovic SF, Carpenter S, Evans A, et al. Myoclonus epilepsy and ragged-red fibres (MERRF) Brain 1989, 112:1231-60.

6 Rosing HS, Hopkins LC, Wallace DC, Epstein CM, Weidenheim K. Maternally inherited mitochondria myopathy and myoclonic epilepsy. Ann Neurol 1985; 17:228-37.

7 Montagna P, Galassi R, Medori R, et al. MELAS syndrome: characteristic migrainous and epileptic features and maternal transmission. Neurology 1988;38:751-4.

8 Shoffner JM, Lott MT, Lezza AMS, Seibel P, Ballinger SW, Wallace DC. Myoclonic epilepsy and ragged-red fiber disease (MERRF) is associated with a mitochondrial DNA tRNAlys mutation. Cell 1990;61:931-7.

9 Ino H, Tanaka M, Ohno K, Hattori K, et al. Mitochondria leucine tRNA mutation in a mitochondrial encephalomyopathy. Lancet 1991;337:234-5.

10 Morgan-Hughes JA, Darveniza P, Kahn SN, Landon DN Sherrat RM, Land JM, Clark JB. A mitichondrial myopathy characterised by deficiency in reducible cytochrome b. Brain 1977;100:617-14.

11 Torbergsen T, Stålberg E, Bless J. Nerve-muscle involvement in a large family with mitochondrial cytopathy. Muscle Nerve 1991;14:35-41.

12 Torbergsen T, Öian P, Mathiesen E, Borud O. Preeclampsia - a mitochondrial disease? Acta Obstet Gynecol eclampsia-a mitocho

13 Berkovic SF, Andermann F, Carpenter S, Wolfe LS. Progressive myoclonus epilepsies: Specific causes and Progressive myoclonus epilepsies: Specific causes and
diagnosis. N Engl J Med 1986;315:296-305.

14 Doose H, Gerken H, Völzke E. On the genetics of EEGanomalies in childhood 1. Abnormal theta rhythms. Neuropaediatrie 1972;3:386-401

15 Morgan-Hughes JA. Mitochondrial diseases. Trends Neurosci 1986;9:15-19.

16 Morgan-Hughes JA, Schapira AHV, Cooper JM, Clark JB. Molecular defects of NADH-ubiquinone oxidoreductase (complex 1) in mitochondrial diseases. $J$ Bioenerg Biomembr 1988;20:365-82.

17 Kroon A, Van den Bogert. Biogenesis of mitochondria and genetics of mitochondrial defects. J Inherit Metab Dis 1987;10(Suppl 1):54-61.

18 Przyrembel $H$. Therapy of mitochondrial disorders. $J$ Inher Metab Dis 1987;10(Suppl 1):129-46. 